\title{
Esclavos en medios eclesiásticos entre los siglos XII-XIV: apuntes para el estudio de la esclavitud en la Edad Media
}

\author{
JOSÉ LUIS CORTÉS LOPEZ
}

Entre los estudiosos de la Edad Media no es frecuente abordar el tema de la existencia de verdaderos esclavos y las monografías sobre esclavitud escasean bastante en comparación con otros estudios. Tal vez toda la atención se dirige al "siervo de la gieba" privado prácticamente de su libertad $y$, por lo tanto, sometido al parecer de sus amos y no se dé el paso siguiente para llegar a seres, casi siempre traidos de paises extranjeros, desprovistos de capacidad y personalidad jurídicas que son auténticos esclavos en el plano sentido de la palabra. Se dispone de ellos como de cualquier cosa y sufren en sus carnes todas las contingencias y posibilidades a las que se somete una mercancia. Heers llega a señalar, como una gran laguna de la historia medieval, la falta de atención a los esclavos y apunta lo que, a su juicio, puede ser la causa: una sociedad cristiana que practicaba una religión cuyo fundamento era la caridad no estaba en consonancia con ese cuadro de miseria humana que los autores habian descrito con respecto a la esclavitud en el mundo antiguo ' $y$, por eso, hay que comprender bien «l'attitude des auteurs des années 1800: esclavage antique, certes, esclavage colonial, oui, car toute société "coloniale» était viciée surtout celle des lbériques, pour une certaine his-

\footnotetext{
' «... les mêmes auteurs considéraient que l'esclavage à l'antique avait complètement disparu dès les premiers siècles du Moyen Age sous l'influence du christianisme et de l'Eglise. Selon eux, la société "chretienne" du Moyen Age n'aurait d'aucune façon pu admettre le maintien d'êtres humains dans une telle condition, et les progrès d'une religion de charité, voire d'égalité par certains aspects, entrainaient forcément l'exaltation de la dignité et de la nature humaines, donc la libération des captifs" (HEERs, Jacques, "Esclavage et domestiques au Moyen Age dans le monde méditerranéen". Paris 1961, pág. 10)
} 
toriographie; mais quant à admettre l'existence de l'esclavage dans son prope pays, en pleine civilisation occidentale, européenne et chrétienne, c'ètait une toute autre affaire..." ?

Pero aunque exista esta causa basada en una mentalidad y, sobre todo, en un prejuicio religioso-moral, a nuestro modo de ver la razón principal por la que la esclavitud ha estado "escondida" camuflada bajo la "servidumbre" ha sido un problema de léxico, porque con la denominación de "servus" (raramente se utiliza "ancilla" en el periodo que estamos considerando) ${ }^{3}$ se pretende designar una amplia gama de situaciones juridicas que va desde el siervo que trabaja libremente el manso recibido de su señor a quien, eso sí, debe ceder una parte del rendimiento de su trabajo en especie y prestaciones, hasta el que vive sin libertad propia dependiendo en todo de la voluntad de su dueño. La falta de palabras definitorias de estados diferentes hace que se dejen al contexto literario la valoración de la situación real de cada "servus», con el riesgo, a veces, de equivocarnos. En España la presencia musulmana habia originado una serie de confrontaciones violentas con los reinos cristianos que hizo aparecer la figura del "cautivo" ("catius") como botin más preciado de los mismos. Este nuevo personaje por el hecho de haber sido apresado en una ocasión bélica, o considerada como tal, perdía toda su personalidad y autonomía pasando a ser una pertenencia de quien le cautivó, de forma que si éste queria podia devolverle su libertad por voluntad propia o mediante un «rescate». El cautivo, pues, era gente extraña o extranjera reducida a un estado de sumisión por actos violentos, pero de ninguna manera eran "por naturaleza" seres sujetos a una servidumbre perpetua, como Aristóteles había querido hacer de algunos componentes de la sociedad ${ }^{4}$.

Frecuentemente ya en la Baja Edad Media en muchos documentos se suele sustituir "servus" o "captivus" por el nombre de la etnia o grupo al

Ibidem.

Y una buena prueba de esto es esta afirmación desafortunada: “C'est seulement dans les pays en contact avec la race africaine, sur les côtes de la Méditerranée et en Espagne, que fon recontre des esclaves dans l'Europe Féodale" (BRuTAlls A, "Etude sur l'esclavage en Roussillon" en "Nouvelle Revue d'Histoire du Droit français et étranger", 1886, págs. 544).

En la documentación que hemos manejado sólo en una ocasión hemos encontrado ambos términos coordinados de forma disyuntiva: "Et si servus aut ancilla venisset inter eos, aut aliquis omo cum alienam uxorem aut sponsa, aut latro iniensiosus, aut aliquis falsatur vel eriminosus, securus stetisset, inter omnes alios abitatores sine aliqua dubitatione..." ("Charta populationis Cardonae, anno DCCCLXXXV" en VILLANUEVA, Jaime "Viage literario a las Iglesias de España», Valencia 1821, t. VIII.)

${ }^{4}$ Politica Lib. I. Caps. II y V. 
que pertenecen: "sarracenus, tartarus, maurus, graecus, slavus...". Este último gentilicio se fue imponiendo quizás por la abundancia de cautivos tomados en las zonas balcánicas, donde una vasta región recibe, precisamente, el nombre de Esclavonia, y de "slavus" se pasó a "esclavus" para designar el estado juridico de aquel que habia visto reducido su capacidad de acción a nada, una vez que se le habia desprovisto de su libertad. Y si al ser sigue el obrar, según uno de los principios lógicos de la Escolástica, los nacidos de estos seres tenian la misma condición que ellos, de aqui que Las Partidas, al hablar de los tres supuestos de servidumbre, dos se refieran a lo que acabamos de señalar: "La primera es de los que cautivan en tiempo de guerra, siendo enemigos de la fe. La segunda es de los que nacen de los siervos. La tercera es cuando alguno es libre y se deja vender" ". Sin embargo, aunque el vocablo "esclavus" tenga su origen en el cautiverio del "slavus", vemos claramente cómo en la documentación del siglo xV y principios del XVI "captivus" y "esclavus" tienen empleos diferentes y expresan situaciones distintas: el cautivo suele hacer referencia a un estado transitorio de pérdida de libertad pero que espera su liberación mediante el rescate y el esclavo designa la condición jurídica de la persona que pertenece a otro. Es sintomático que cuando "esclavus" pasa a designar un contenido juridico vaciándose de todo pose gentilicio, la palabra "servus" desaparece o se hace rarisima para definir lo que en realidad es un esclavo; y mientras podemos encontrar en expresiones literarias las combinaciones "siervo y cautivo" o "esclavo y cautivo" como adjetivos o atributos de un mismo nombre, no hemos dado con el empleo de "siervo y esclavo" en las mismas circunstancias.

Esto puede darnos la clave de que, si en un principio, el empleo de "servus" podia designar, como hemos dicho, una amplia gama de situaciones entre ellas la que entendemos por esclavo, cuando se invente «esclavus" ya no hará falta acudir a "servus" o recurrir al contexto para designar a la persona que pertenece a otro. Ambos términos nos expresarán dos conceptos diferentes aunque muy próximos en su significado. Nada mejor para ilustrar lo que acabamos de decir que estas palabras del escolástico Suárez:

\footnotetext{
S Partida IV, Tit. XXI, Ley 1
}

En las "Consuetudines illerdenses" en el aparato "De hostibus» se puede leer: "Quilibet in guerra potest capere suum guerrarium et tenere ubicumque vult, et compellere redimere et sibi totam redemptionem habere..." (Lib. II). En VillanueVa, O.C. T. XVI, págs. 15 y 160 . Se escribieron en 1228 por Guillermo Botet; Villanueva dice que sacó el texto de un códice propiedad de un particular y que lo cotejó con otro del archivo "secular" y con un tercero existente en una iglesia. 
«... la subordinación de la servidumbre, no tiene la vil condición del esclavo, porque no priva absolutamente de la libertad y no pone al siervo bajo el domino de propiedad del señor... A pesar de todo no habia existido en el estado de inocencia esta clase de dominio. Porque aunque la servidumbre no sea de tal vil condición como lo es la esclavitud, sin embargo conviene con ella en que toda la potestad del señor sobre el siervo se ordena a la utilidad del señor. Por este sentido la servidumbre participa mucho de la condición servil..." ${ }^{6}$.

Nos ha parecido oportuno hacer estas disgresiones sobre la nomenclatura porque, precisamente, las palabras-clave de este articulo «esclavo-esclavitud" no se encuentran empleadas en la práctica totalidad de la documentación que hemos manejado para confeccionarlo.

\section{GRUPOS ÉTNICOS Y SU PROCEDENCIA}

Excepto en dos casos en que se habla de «negros» y en otros dos en los que no se dice nada de su origen utilizando el nombre genérico de "cautivos", en todos los demás se los designa como "sarracenos" cambiándose en una ocasión este nombre por el de «maurus». Estamos, pues, ante una verdadera esclavitud fuera de las dudas que pudieran surgir si se hubiera utilizado !a palabra "servus". Lo que si conviene aclarar cuanto antes es que más que describirnos las caracteristicas étnicas de los esclavos, lo que hacen los documentos es denominarlos por un concepto religioso $\mathrm{y}$, como ya hemos tenido la experiencia de constatar en documentación posterior, a esclavos de raza negra también se los incluye dentro de moros o moriscos, por lo que en nuestro caso no sería extraño que bajo la denominación de "sarraceno" pudiera esconderse algún negro que, como sabemos, se irá constituyendo en protagonista absoluto de la esclavitud a partid del siglo xv.

No obstante, uno de los documentos que nos hablan de cautivos de esta raza es, por ahora, el documento más antiguo que hemos encontrado sobre la presencia en España del esclavo negro. Sin duda ninguna que puede haber otros que nos hagan retroceder aún más en el tiempo, porque la llegada árabe, y más concretamente la afluencia bereber que viene a instalarse en la peninsula constituyendo la base de no pocos reinos, 
arrastró consigo gran número de esclavos negros ("harratin») de los que se servian tanto en los trabajos corrientes como en el ejército. Estos negros podía caer en manos de cristianos como botín de incursiones y cabalgadas y también como parte del precio pagado por un rescate. En espera, pues, de encontrar otros documentos que nos abran horizontes más antiguos de la presencia del esclavo negro en España, nos quedamos hoy por hoy con el siguiente:

«Ego Arnallus Mironis et coniux mea Arsendis... facimus hanc scripturam nostrae donationis... Sciatus a cunctis quia pro defensione ecclesiae Agerensis feci ego offerenda a domino apostolico Nicholao quince millia solidos aureos Valentiae: similiter a dominio apostolico Alenxandro tria millia solidos aureos Valentiae et decem captivos nigros. Hoc totum etiam facimus pro redemptione animarum nostrarum..." '.

El documento está fechado el 4 de abril del año VIII del rey Felipe que corresponde al 1067. Las donanciones se hacen, pues, a los papas Nicolas II y a su sucesor Alejandro II para obtener la defensa y sujeción de la iglesia de Ager a la de Roma.

El mismo documento nos hace ver la forma de cómo muchas de sus riquezas llegaron a poder de este señor: «Et advenerunt nobis praelibata omnia per voluntaten Dei, qui nobis hoc dedit de potestate sarracenorum, et per nostram aprisionem, sive per emptione, atque per alias omnes voces...". Interesante este apunte porque prácticamente nos pone en camino de adivinar la procedencia de los «decem captivos nigros" que Arnaldo dona al papa: con toda probabilidad procedian del botín obtenido por alguna incursión en territorios musulmanes. $Y$ cabe pensar también que los cautivos sarracenos en poder de eclesiásticos, sobre todo de los obispos de los que aqui hacemos referencia, tienen ese mismo origen, como se puede desprender del privilegio que Jaime I concede a la iglesia de Santa Maria de Teruel dándole derecho a participar del botín conseguido en las cabalgadas donde se encuentre el pendón del la villa ${ }^{8}$.

Aunque la procedencia última de los esclavos sea la cautividad por acciones violentas, una vez que están en medios cristianos por ventas,

\footnotetext{
Este documento lleva el número 69 del Archivo de la lglesia de Ager y reproducido en VILLANUEVA, O.C. T. IX, pág. 255. A éste y a otros documentos transcritos por este autor hemos querido tener acceso directo para comprobarios personalmente, pero sin resultado positivo pues, al parecer, las vicisitudes politicas y los traslados indiscriminados de los fondos documentales han hecho que no se encuentren muchos de ellos en el lugar donde él los consultó. Los 776 documentos repartidos en los XXIII volúmenes de su obra deben considerarse, pues, una colección inestimable y, en mischos casos, una fuente de primer orden.

${ }^{\circ}$ Archivo de la Catedral de Teruel. Pergamino n.. 1.
} 
donaciones $u$ otros procedimientos pueden ir distribuyéndose a personas $\mathrm{e}$ instituciones que no participaron en dichas acciones. En el ambiente eclesiástico del que nos ocupamos, la donación es, tal vez, el método que más abunda para la repartición de los mismos y se suele manifestar frecuentemente en el testamento al disponer del destino que se ha de dar a los bienes propios. Guillermo de Peratallada, obispo de Gerona, deja en 1169 varias pertencencias al hospital de Jerusalén y, entre ellas, "dimitto ad hoc idem sarracenos meos et omne meum argentum». Pedro de Castronovo, obispo también de la misrna ciudad, entrega "pro captivis redimendis Johannem nigrum batizatum" y para un colega suyo "dimittimus domino Episcopo Valentiae Bafumetum sarracenum nostrum" (año 1278), Raimundo Rocaberti, obispo de Tarragona, expone también en su testamento que «soivantur et paccentur legata mea de annona mea et vino meo et captivis et omnibus aliis rebus meis mobilius et expletis praesentibus et futuris". (Año 1214). No sabemos el número de esclavos que este obispo podía tener, pero por el contexto se deduce que debian ser algo numerosos a juzgar por las expresiones empleadas: al monasterio de Santa Cruz deja «unum sarracenum qui vocatur mafometh, et alium sarracenum de melioribus bacallaris quos habeo..." ${ }^{9}$.

Las donaciones a monasterios son muy frecuentes y asi encontramos al arzobispo Sparagi, de Tarragona, que dirigiéndose a Randolfo, prior del monasterio de cartujos de Scala Dei, le hace la siguiente concesión:

«... damus et assingamus praefato Priori et successoribus suis fratribus dictae domus Sacalae Dei omnes illos sarracenos nostros et sarracenas de Benilafet, cum omnibus juribus et dominio, quae ad nos pertinent, sine retentione aliqua in eisdem, totis temporibus vitae nostrae. Et si dictus Prior aut successores ejus, vel fratres dictae domus a Sede Apostolica hoc potuerunt obtinere, praefatum domum per nos et successores nostros in perpetuum sine contraditione aliqua eis concedimus todo corde..." (Año 1220) ${ }^{10}$.

En este mismo sentido encontramos también al arzobispo de Toledo que hace concesión "perpetua" de "moros y moras siervos y siervas" al dean y cabildo de la Colegiata de Talavera de la Reina en $1325^{11}$, y a un particular que da a la iglesia de Oviedo unas propiedades con seis «mau-

VIllanueva, Ob. cit., t. XIII, págs. 289 y 322; t. XIX, pág. 269.

Ibidem, t. XiX, pág. 310.

"Archivo de la Colegiata de Talavera de la Reina. Carpeta 561, n." 10. Toledo 3 de enero de 1325 
ros" ${ }^{12}$. Este caso puede llamar la atención por su situación alejada de las zonas de conflictos, lo que nos hace suponer que estos moros han llegado alli como producto de alguna venta. También nos ponen de manifiesto que la práctica de la esclavitud, con más o menos intensidad, se practicó en todas las zonas de España. Otro ejemplo de esto mismo lo constituye el monasterio de Osera, en Galicia, cuyo abad obtiene una provisión de Pedro I ordenando a los concejos gallegos que entreguen al monasterio seis moros y moras cautivos con sus hijos y nietos que habian huido ${ }^{13}$.

\section{SOBRE ALGUNOS ASPECTOS SOCIOECONÓMICOS}

Por lo que nos deja ver la documentación, el tipo dominante es una esclavitud doméstica que presta sus servicios dentro de la casa del amo o en actividades directamente relacionadas con la misma. Sin embargo, hay que pensar que también existe un aprovechamiento de su trabajo fuera de lo estrictamente doméstico cuando los esclavos están en alguna propiedad de su amo, como los que tiene el arzobispo Sparagi en Benilafet, o los que sean propiedad de un monasterio. En estos casos su actividad principal es el trabajo agricola y ocupaciones orientadas al mismo, por lo que, en parte, se puede hablar de «explotación» de la mano de obra esclava utilizando una expresión actual. Incluso había una especulación sobre ciertas prestaciones "torpes" de algunas esclavas a quienes ciertos dueños enviaban los fines de semana a prostibulos para lucrarse con el dinero proveniente de actos propios de estos recintos ${ }^{14}$. No debian

\footnotetext{
1090.

${ }^{12}$ Archivo de la Catedral de Oviedo: "Liber testamentorum». Fol. 108, 8 de marzo de

${ }^{13}$ A.H.N. Sección "Clero"; "Libro de los Privilegios". Fol, 116 Tambièn encontramos a los reyes haciendo regalos a la Iglesia entre los que no faltan los esclavos. Alfonso 11 y y su mujer doña Jimena por el bien de sus almas y las de sus hijos dan al obispo Recaredo utensilios y ropas litúrgicas, libros y 50 esclavos musulmanes para la diócesis de Lugo. (Tumbo viejo de la Catedral. N. ${ }^{\circ}$ 57, Fols. 28-30. 30 de junio 897).

Alfonso II en 1286 dona 11 sarracenos cautivados en Menorca al monasterio de Montserrat (MiRet Y SANS, J., "La esclavitud en Cataluña en los últimos tiempos de la Edad Miedia" Revue Hispanique XLI, 1917, págs. 1-109)

14 «tem monemus primo, secundo, tertio, et peremptorie omnes et singulas personas, cuisvis gradus, status vel conditionis existant, habentes vel tenentes servos ad servicium proprium, vel etiam septimanam, quae de turpi et fedo questu querunt et adquirunt in lupanari vel alibi manifeste lucra turpia atque feda pro solutione septimane huiusmodi, vel alicuius emolumenti, seu lucri dandi eisdem personis, ne de cetero audiant seu presumant haec facere sive pati modo aliquo tacite vel expresse, sub pena ex-communicationis..." («Constituciones Sinodales de la Iglesia de Mallorca», según el sinodo alli celebrado en 1935 y extraidas «Ex manuali negotiorum Capituli Maioricensis ab anno 1391 ad 1399. VILLANUEVA, Ob. cit., t. XIl, pág. 278).
} 
estar exentos los eclesiásticos pues hay también para ellos una grave admonición:

"mandamus etian universis et singulis praesbiteris et clericis beneficiatis in nostra diocesi, ne aliquos servos vel aliquias servas teneant vel habeant ad aliquam talliam seu septimanam.

Quinimo si quos vel si quas habuerint, nunc pro tunc dictos servos liberamus a iugo servitutis et ab onere talliae seu septimana eorum, et ipsos ac ipsas penitud infranquimus..." ${ }^{15}$

Este texto, perteneciente a la iglesia mallorquina, nos permite conocer como el clero podia tener esclavas para servicio propio, como también las encontramos entre los clérigos de otras iglesias, aun cuando hay muchas disposiciones particulares que prohiben la presencia de mujeres sospechosas en casa de los mismos. Esto quiere decir que a la esclava se la consideraba como algo inocuo e incapaz de comprometer la buena reputación del clérigo, precisamente por su consideración y posición juridicas que hacian de ella alguien con quien parecia imposible una "cohabitación». Así en las "Constituciones Sinodales" de la iglesia de Urgel se declara:

«... Inhibemus districte ne clereci feminas teneant de quibus suspicio mulieres, matres, sorores, amittas et consanguineas secum in domibus Ecclesiarum tenere presumant, sed alibi, si pauperes fuerint eis poterunt neccesaria ministrare..."

En el sinodo gerundense:

"A presbitero usque ad subdiachonum, si uxorem duxerint aut concubinam retinuerint, de coro exeant, et omne beneficium ecclesiae perdant et cum laicis in ecclesia maneant. Quod si inobedientes extiterint, sententiam de incestis incurrant". $Y$ en las disposiciones leridanas volvemos a encontrar la misma idea: «Nullus sacerdos habeat in domo sua aliqua occasione mulierem, nisi sit mater eius aut soror..." ${ }^{15}$.

Llama, pues, la atención la ausecia de una mención directa a las esclavas cuando en disposiciones concernientes a otros aspectos se las cita

${ }^{15}$ Constituciones Sinodales de Urgel: "De vita et honestate clericorum». Año 1276.

Sínodo Gerundense del año 1068, n. ${ }^{\circ}$ VII.

Constituciones sinodales ilerdenses, sin fecha, pero confeccionadas bajo el Obispo Raimundo de Ciscar entre 1247 y 1252. (VILlanueva, Ob. cit., ts. XI, XIII, pág. 261 y XVI, pág. 302, respectivamente). 
como formando parte del entorno del clérigo si las tiene. Volvemos a insistir en que la baja estima hacia la esclava no parece que constituya un peligro para la castidad del clérigo. Tan rara y grave parecía una unión de este tipo que la mencionada constitución de Urgel equipara la relación con judia o sarracena (y la mayor parte de las esclavas lo eran) a la brutalidad, consitituyendo, por lo tanto, un pecaso «ad Episcopum recurrendum» ${ }^{16}$.

La compraventa era el otro gran canal de distribución del esclavo y que abria la posibilidad de que su presencia se advirtiera en lugares alejados de las fronteras donde tradicionalmente la esclavitud ha tenido poca raigambre. Varias de las ventas que hemos encontrado en este pequeño estudio se realizan en cláusulas testamentarias por lo que el dueño, que no va a percibir el beneficio de las mismas pone ciertas condiciones a la transacción o destina el dinero resultante para determinadas acciones. Del obispo Pedro de Castronovo ya hemos visto cómo entrega un negro para la redención de cautivos, pero tambièn: «caeteros autem batizatos et sarracenos mandamus vendi... ita tamen quod non possint ad manus infidelium devenire...". La precisión del obispo de no vender sus esclavos a los infieles deberia entenderse sólo de los sarracenos, pues estaba prohibido vender cristianos a personas de otra ley, si bien entre cristianos se podía comerciar con esclavos aunque estuvieran bautizados. En el sínodo celebrado en Barcelona en 1244 bajo el obispo Pedro de Centelles, se encuentra la siguiente constitución:

«Poena illorum, sive sin clerici sive layci, qui christianum vel christianam vendunt sarracenis talis est quod ipso iure sunt excommunicati, nec possunt absolvi nisi a Sede Apostolica, secundum constitutionem D. Sabinensis: Statuimus uti quicumque...” ${ }^{17}$.

${ }^{16}$ Entre los casos reservados al obispo se cita: “item illi qui cum Judea, Sarracena, vel bruto animali coire ausu temerario, alias nephario presumpserint..." (Constituciones Sinodales de Urgel. Año 1276. VILlanueva, Ob. cit., t. XI).

17 Constituciones del sinodo celebrado en Barcelona el 6 de noviembre de 1244: “De christianis qui vendunt Sarracenis christianum». VILlanuEva dice que encontró este códice en la biblioteca de los Carmelitas Descalzos. En el apartado “De clericis non deferentibus coronam" también encontramos la siguiente alusión: "Item mandat D. Episcopus nautis, marinariis et omnibus aliis navigantibus, ne ad partes Sarracenorum baptizatos, sive quoscunque alios christianos portare presumant praeter uxores propias, nec illas etiam sine speciali licenti Episcopi, cum quidam quandoque fraudulenter dicant se esse conjuges qui non sunt, quos nautas, marinarios, et alios qui contra huiusmodi mandatum veniant, Juan D. Episcopus excommunicavit, et fecit eos excommunicatos publice nuntiari..." (VILLANUEVA), Ob. cit. t. XVI, pág. 348 y 350). A este respecto hay que recordar que el Concilio de Viena (13111312) volvió a insistir en que los esclavos bautizados no fueran vendidos a los infieles. 
Por su parte, el arzobispo de Tarragona, Hugo Cervelló, deja sus esclavos con otras cosas para las obras de la catedral: "medietatem vero panis et vini quae habebat, et sarracenos et ademulas suas et anulos suos minores quos in capella habebat operi ecclesiae dedit.... Intuimos que debe tratarse de la catedral porque en aquellos momemtos la iglesia titular era la de Santa Tecla ${ }^{18}$. Algunas disposiciones del ya citado arzobispo Rocaberti son sorprendente y curiosas porque nos ponen delante de un hecho bastante sorprendente como es la copropiedad:

«Recognosco quod Arnaldus de Sardinia habet quartam partem in quatuor sarracenis quos habeo cum eo, et dimitto ei ducentos solidos super ipsis sarracenis et aliis rebus meis. Laudo et concedo Johanni Thomae partem quam habet in sarracenis quos habeo cum eo sicut scriptum est in albarano...".

No entendemos bien el gesto del arzobispo de pagar a su socio 200 sólicios: si es porque le debe esa cantidad en concepto de alguna deuda sobre la propiedad de los esclavos, en cuyo caso reafirmase esa propiedad que pasará a sus herederos o, por el contrario, si esos sólidos los entrega como pago de esa cuarta parte quedándose sus herederos con la propiedad completa. En el segundo caso está claro que renuncia a la parte que le corresponde en otro lote de esclavos. La copropiedad sobre un esclavo es tal vez la prueba más evidente de su nula condición jurídica y su equiparamiento a cualquier cosa material que se puede compartir o dividir. Tampoco era un hecho tan raro y hemos tenido ocasión de comprobarlo con alguna frecuencia en épocas posteriores ${ }^{19}$, lo que pone de manifiesto el no reconocimiento de su personalidad.

La compraventa debia hacerse con todas las garantias materiales y espirituales. En el primer apartado entraban las buenas condiciones en que debia ofrecerse la mercancia o, si habia defectos, debian manifestarse para que la operación no estuviera viciada en su origen y no hubiera lugar a futuras reclamaciones y posible declaración de nulidad. Al tratarse de la venta de una persona habia también que manifestar posibles mutilaciones fisicas, su comportamiento, que hoy llamariamos "psiquico", y sus tendencias. Entre las garantias espirituales la primera condición era asegurar que el esclavo habia sido hecho tal en «buena guerra", o sea, en guerra justa. El hecho de combatir contra los «enemigos de la fe» era

18 Testamento de 1171. (VIllanueva, Ob. cit., t. XIX, pág. 265).

${ }^{19}$ CoRtés LOPEZ, J. L., "Los origenes de la esclavitud negra en España», Salamanca-Madrid 1986, págs. 136-137. "La esclavitud negra en la España peninsular del siglo xvl», Salamanca 1989, págs. 81-82. 
ya un motivo suficiente para que la guerra cumpliera tal requisito. El primer deán de Lérida, Arnaldo de Vernet, compró en septiembre de 1267 una esclava blanca sarracena, llamada Axa, a un señor de Alcañiz. En la escritura de venta que figura en su poder el vendedor le asegura que:

"non mingit in lecto, nec est tolta, rapta sive furata, nec est de pace vel tregua domini regis Aragon, vel regis Catellae, nec de aliquo loco suspecto, nec est demoniacha seu guta cadens, ne stulta, aut christiana, immo est sarracena et filia sarraceni et sarracenae» ${ }^{20}$.

Esta forma de garantizar la buena salud del esclavo se convierte en un formalismo que encontramos en las cartas de compraventa de los siglos posteriores y que se plasmará en un modelo propuesto por el moralista Pedro de Melgarejo hacia mitad del siglo XVII ${ }^{21}$.

Los precios que aparecen en los casos de compra que estamos considerando son bastante dispares: "Volo ut solvantur Bernardo Gibot C solidos pro sarraceno quem habui a patre suo», se lee en el testamento del arzobispo Rocaberti en 1214, mientras que por Axa el deán de Lérida dio 72 sueldos en 1267 y un templario de la Casa de Barberá compra un cautivo por 65 "sous» en la feria de Tarragona ${ }^{22}$. Estos datos son precarios para hacer una lista de precios exhaustivo, pero, al menos, si nos van a permitir establecer una aproximación a un valor medio del esclavo y a un evolución de su precio hasta el xvı. Si aplicamos la paridad existente en

20) Villanueva, op. cit. T. XVI, pág. 64.

"Por ejemplo, en nuestras investigaciones en el Archivo de Protocolos Notariales de Salamanca descubrimos gran cantidad de documentación referente a esclavos y, entre ella, numerosas cartas de venta conteniendo los mismos elementos que los citados en la carta del deàn: «... la qual vos doy e vendo porque la obe de buena guerra e que no es borracha ny fugitiva ny ladrona ny endemonyada ny que tiene gota coral ni otro viçio alguno ny mal contagioso..." (Leg. 3372. Fols. 191-692. Año 1533).

«... el qual os vendo por avido de buena guerra sujeto a servydumbre e por sano que no es manco ni tiene gota coral ny es beodo ny se enbeoda ny mea ni ensuçia en la cama ny es fugitivo ny tiene espiritus ny enfermedad encubyerta..." (Leg. 3146. Fols. 150-151. Año 1541).

Pedro de Melgarejo incorporó a su obra un modelo de carta de venta de esclavo en la que comprendia la forma en que tradicionalmente se habia hecho y se hacía tal venta. En

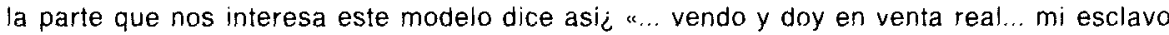
o esclava, cautivo habido de buena guerra... sano de toda enfermedad pública o secreta. de mal de corazón, bubas, ojos claros sin ver, no fugitivo ni ladrón, borracho ni otro ningún defecto ni tacha que le impida servir bien..." (Compendio de Contratos Públicos. Granada 1625, pág. 20)

2 Miret y Sans, O.c. 
este siglo del suelo $=12$ dinero y un dinero catalán $=1,30$ maravedies $^{23}$, tendriamos que, aproximadamente, un esclavo rondaria entre los 800-900 dineros que, traducido en maravedies del siglo XVI, vienen a ser 1040-1170 ${ }^{24}$. Según nuestros estudios, el precio medio del esclavo negro en la segunda mitad del siglo xv fue de 8.000 maravedies la mujer y 6.774 el hombre $y$, a finales del xvI, el esclavo se cotizó a unos 85 ducados, o sea, 29.750 maravedies ${ }^{25}$. Es decir, entre el siglo xili y finales del Xvi el precio medio del esclavo conoció un aumento aproximado del 2.600 por 100 .

\section{BAUTISMO, TRATO Y LIBERACIÓN}

Uno de los fines últimos justificativos de la esclavitud era precisamente hacer cristianos a los «enemigos de la fe» y enseñarles las verdades de la doctrina cristiana bajo la custodia de su amo a quien, por otra parte, incumbia esta responsabilidad y si, como en nuestro caso, el dueño era un eclesiástico, ésta era aún mucho mayor. No obstante, el bautismo en el caso de los sarracenos era un obstáculo insalvable para su rescate, por lo que muchos propietarios anteponian los beneficios de éste al consuelo de la religión. Sin embargo, para el clérigo no dejaba de ser un cargo de conciencia y así leemos al final del testamento de un tal Ponce, canónigo de Gerona y "capud scolae», "Et jubeo ut faciant babtizare sarracenum meum et sarracenam propter remedium animae meae» ${ }^{26}$. Los escrúpulos experimentados por este eclesiástico en orden a su salvación le llevan a imponer un sacramento a unos esclavos suyos de los que, a lo mejor, no se habia preocupado durante su vida y manda que otros suplan esta deficiencia.

23 Tomamos la paridad propuesta por AliAgA Girbes, José, "Los tributos e impuestos valencianos en el siglo xvı. Su justicia y moralidad según Fr. Miguel Bartolomé Salón, O.S.A». Roma 1972, Apéndices.

${ }^{24}$ Insistimos que se trata del valor del maravedi en el siglo xvi, que es lo que más nos conviene para tener una idea de la evolución del precio del esclavo. Su devaluación con respecto a la moneda de Cataluña, Aragón y Valencia fue bastante grande. Asi, a principios del siglo xIv 1 maravedi se cotizaba a 7 sueldos jaqueses en Daroca, mientras que el «Fuero de Cáceres" que nombra también el "sueldo" como moneda, parece que se daban 7,50 de éstos por maravedi, siendo 10 dineros el valor de cada uno de éstos. (Floriano, A. G., "Documentación histórica del Archivo Municipal de Cáceres (1)". Cáceres 1934). Según esta equivalencia, la sarracena Axa valdría unos 10 maravedies del siglo xill más o menos.

${ }^{25}$ Cortés Lopez, J. L., "Los origenes...", pág. 107. “La esciavitud negra...", pág. 136.

26 Villanueva, O.c. T. XII, pág. 306. Año 1064. 
En auxilio de la Iglesia estaba el poder monárquico que intentaba por todos los medios la conversión de los musulmanes como el mejor método de asimilación, de aquí que estuviera también interesado en apoyar todas las iniciativas para conseguir este intento, aunque fuera en los sarracenos cautivos. Ahora bien, el hecho de recibir el bautismo no era el camino para un liberación directa, pues si bien Las Partidas ${ }^{27}$ disponian que si un esclavo de judio, moro o hereje se convertia al cristianismo quedaba libre sin pagar ningún precio por su liberación, el esclavo de un dueño cristiano no corria la misma suerte con su conversión. La realidad era que el espiritu de la legislación más que favorecer al esclavo convertido era incomodar a moros y judíos en otros aspectos más y castigar a los herejes por su desviación. De todas formas no se llevó esto al pie de la letra porque hemos encontrado esclavos bautizados bajo poder de gente de otra ley sin que por esto hayan recibido una liberación automática. Con respecto al caso de los herejes, la Inquisición habia acordado ampliar el panorama liberador de los esclavos decretando la liberación de los mismos cuyos propietarios hubieran sido "reconciliados» por algún tribunal del Santo Oficio ${ }^{28}$. Pero esta generosa oferta quedó anulada por las disposiciones de 1500 que ordenaban que estos esclavos arrancados de los "reconciliados" se pusieran a servir con otros amos que les dieran un trabajo razonable pagándoles el salario correspondiente ${ }^{29}$. Es decir, los ponian en una situación de servidumbre permanente en cuya tramitación y a cuyo amparo ciertos responsables inquisitoriales se apropiaban de algunos de ellos ${ }^{30}$.

Volviendo a nuestro punto de partida traemos, a este respecto, una carta de Felipe de Mallorca, que gobierna como tio y tutor de Jaime III, fechada en Perpiñán el año 1327. Como se puede observar es un texto ponderado y hasta atractivo por su llamada a las buenas formas y recha$z 0$ de la violencia, pero que no oculta la realidad: con bautismo o sin él el esclavo seguirá siendo esclavo:

«Rursum mandamus vobis... et rogando illis dicatis, quod ipsi in confessionibus, quas audient, confitentes moneant et inducant viis et modis licitis quibuscunque, et sine violentia et opressione quacunque quod ob reverentiam Dei et animarum suarum et captivorum suorum salutem, gratis permittant et sustineant babtizari pueros captivos, et alios quos

\footnotetext{
"Partida IV, tit. XXI, Ley 8 y tit. XXII, Leyes $1,3,5,6,7$

${ }^{2 H}$ Instrucciones de 1484. Cap. XXIV.

${ }^{29}$ A.H.N. Inquisición Leg. 1225.

${ }^{30}$ Cortés Lopez, J. L., "La esclavitud negra...", págs. 80-81.
} 
habent, absque praeiudicio iuris eorumdem quod habent in captivis eisdem: cui iuri per ipsum babtismum et servituti ipsis dominis praeiudicium nullum fiat..., ${ }^{31}$.

Además de preocuparse la Iglesia por el bautismo de sus esclavos, también lo hizo por otros aspectos relacionados con su fe y costumbres, siendo uno de ellos el descanso preceptivo los domingos y dias de fiesta. El esclavo, que se le tenía para trabajar, parecía no estar obligado a guardar este descanso y, menos aún, si no estaba bautizado. Sin embargo, tanto los poderes religiosos como los políticos dan órdenes y establecen disposiciones imponiendo a los amos el reposo dominical que puede ser aprovechado también para la instrucción cristiana de los cautivos bautizados. La reiteración con que vemos la promulgación de estos mandatos, primero en la Península y posteriormente en el Nuevo Mundo, nos hacen pensar que frecuentemente se sometía al esclavo a sus trabajos ordinarios incluso en los dias festivos. Por esto, una de las disposiciones del sínodo de Mallorca hace hincapié en la observancia de este precepto imponiendo a los curas que vigilen a los parroquianos para que sus siervos no trabajen los dias señalados "aliqua opera ruralia vel servilia aut manualia" bajo pena de que no puedan entrar en la iglesia; a los curas que no denuncien estos casos se les impone una multa de 10 libras:

"quam penan etiam extendi volumus omnibus et singulis presbiteris el clericis nostre diocesis in sacris ordinibus constitutis, qui habeant et teneant servos vel servas praedictas, et permisserint, fecerint seu consenterint, et non prohibuerint fieri opera supra dicta..." ${ }^{32}$.

Lo que quiere decir que también los clérigos, a veces, rehuian esta obligación y hacian trabajar a sus esclavos los dias de fiesta.

$Y$ si olvidaban cumplir alguna vez el precepto eclesiástico que tan de cerca les tocaba, a lo mejor también pasaban por alto en ciertos momentos la obligación de darles un trato correcto. Es una suposición, porque de la lectura de los documentos que hemos manejado no se puede emitir un juicio valorativo sobre la relación señor-esclavo. Tratándose en su mayoria de esclavitud doméstica en medios un tanto selectos nos inclinamos a pensar en un trato correcto, pero, insistimos, las fuentes de que nos hemos servido para este trabajo hablan de la esclavitud sólo de modo tangencial en cuanto formaban parte de unas relaciones sociales en las

"Villanueva, O.c. T. XXI, pág. 303.

32 Ibidem, t. XII, pág. 278: "EX manuali..." n." VI 
que estaban inmersos también los eclesiásticos. No obstante, por el hecho de ser esclavos podian ser sometidos a penas más severas que los demás ciudadanos y, a veces, por sólo sospechas. Dentro de este contexto podriamos situar este hecho:

«1374. Die sabbati VII mensis octobris, anno a Nativitate Domini M.CCC.LXXIV., quatordecim servi Sarraceni, et neophiti act Tartari fuerunt suspensi per plateas civitatis ex eo quia voluerunt ignem ponere per diversa loca dictae civitatis et terram ac regnum Maioricarum sibi ipsius retinere, ac Regi Sarracenorum tradere, Dominum Regem Aragonum inde penitus ab eodem removendo seu alias expoliando" ${ }^{33}$.

Este documento es también significativo por la denominación de «tartari» que da a algunos de los esclavos y de lo que ya hemos hecho mención al principio. No es preciso que este gentilicio haga expresa referencia a la zona actual de la Tartaria, sino que simplemente denota su origen mediterráneo oriental, pudiendo tratarse de esclavos traidos de alli por comerciantes mallorquines muy en contacto con aquellas zonas o los que se trajeron a raiz de la presencia almogávare que, a tenor de ciertas crónicas, fueron muchos ${ }^{34}$. Cinco ar̃os más tarde se nos vuelve a hablar de otra sarracena de un tal Raimundo Oliverio que quemaron "quia administraverant et fecerant aliquas perfumaciones adversus uxorem dicti Raimundi Oliverii..." La reputación de magas y hechiceras que tenian las esclavas moriscas era un hecho en el siglo xvı, probablemente fruto de un prejuicio tradicional y comportamientos como el de esta esclava, no fueron raros muchas veces por tratar de vengarse de los malos tratos. Tras la muerte misteriosa de Escobedo y el proceso que se entabla contra Antonio Pérez, en una de las declaraciones de éste se lee «que se recelaba Escobedo de que le habia dado hierbas una esclava y pedia que se tratase de ello..." ${ }^{35}$. Al parecer, una esclava suya habia intentado envenenarle porque sus dueños la habian pegado. Fue ajusticiada siendo ahorcada.

${ }_{3}^{3}$ Ibidem, t. XXI, pág. 218. Villanueva toma éste y otros acontecimientos del notario maIlorquin Mateo Sallet que apunta al principio y al final de sus legajos protocolarios los sucesos vividos en su ciudad desde 1372 a 1408 .

${ }^{34}$ Nada mejor para ilustrar esto que este pequeño párrafo. de D. Francisco de Moncada:

"Porque el tiempo que los nuestros estuvieron en Asia fue muy poco, y este le ocuparon siempre en vencer y alcanzar señaladas victorias de sus enemigos de donde les resultaba infinita ganancia de las presas que hacian, que era tantas que, algunas veces, las dejaban, o por no poderlas llevar o por estimarlas en poco...".

("Expedición de los Catalanes y Aragonenes contra Turcos y Griegos". Cap. XVIII).

${ }^{3}$ Colección de Documentos Inéditos para la Historia de España. T. XII, pág. 26. 
Los esclavos, además de estar sometidos a la jurisdicción de su dueño, estaban también, lógicamente, bajo la autoridad civil que disponia para ellos sanciones especiales, frecuentemente superiores a las aplicadas a la personas libres para un mismo delito. El responsable de los desperfectos y desmanes de los esclavos eran los dueños quienes tenían la obligación de repararlos. En caso de que hubieran tenido que pasar por la cárcel tenian que pagar los gastos generados en la misma que, por ejemplo, en Mallorca era de dos dineros diarios a finales del siglo XIII:

«... otargant a tots los homens de la ila de Mayorcha fora la ciutat habitants... que per si o per missatges o per missatges o per catius lurs, negun temps no sien tenguts de dar en pagar per carcelatge de la preso, en la quel el o alam dels, o alguns missatgers o catius lurs preses seram o detenguts, axi en la ciutat com de fora, sino II diners de reyals tan solament cada dia per cada persona, axi com los ciutadans els habitadors de la ciutat de Mayorcha donen e pagen lo carcelatge damunt dit.... ${ }^{36}$.

Finalmente, entre las diversas formas de liberación o ahorramiento que se podian emplear para hacer franco a un esclavo, aqui nos encontramos sólo con la cláusula testamentaria utilizada en dos ocasiones. Era este método uno de los más empleados, pues se pensaba que haciendo esta obra de caridad era una buena preparación antes de presentarse al juicio de Dios. Así leemos en el del obispo Pedro de Castronovo: «ltem enffranquimus matheum batizatum nostrum» y en el de Fray Pedro de Centelles:

"Manumittimus etiam post obitum nostrum et liberos facimus Bartholomeum, cochum nostrum, et sororem ejus Guilleiman et filios eorum habitos et habendos omnibus bonis suis..." ${ }^{37}$.

A veces, la liberación por testamento ocasionaba serios conflictos a los mismos esclavos que veian su libertad amenazada por la avaricia de los herederos. Cuando así sucedía, éstos hacian todo lo posible para revocar esa cláusula testamentaria y quedarse con ellos o, simplemente, no la llevaban a efecto. Si el esclavo conocia tal disposición podia, entonces pleitear contra los herederos siendo éste el único caso, junto al que habia recibido dinero para ahorrarle y luego no lo hacía, en que el esclavo podia presentarse ante los jueces de forma autónoma sin necesitar la au-

36 Villanueva, O.c. T. XXII, pág. 285. Año 1284.

37 Ibidem, t. XVI, pág. 354. Barcelona 23 marzo 1251. 
torización de sus amos ${ }^{38}$. No sabemos si estas personas liberadas en ambos testamentos tuvieron que pasar por este trance, cosa que creemos no sucediera, sino que en ellos se realizó el cumplimiento de la voluntad de sus dueños y que, por esto mismo, se constituyó en su derecho y «todos los derechos del mundo ayudaron siempre a la libertad" ${ }^{39}$.

${ }^{38}$ Partida III. Tit. II, Ley 8

${ }^{39}$ Ibidem, tit. V, Ley 4. 